\title{
Del paso de la guerra a las resistencias corporales*
}

\author{
From the passage of the war to the corporal resistances
}

Desde a passagem da guerra às resistências corporais

\author{
Gaviota Marina Conde Rivera** \\ Universidad Santo Tomás, Bogotá, Colombia. \\ Correo electrónico: gavioaconde@usantotomas.edu.co \\ Revista Corpo-grafías: Estudios críticos de y desde los cuerpos / Volumen 5 - Número 5 / Enero - diciembre de 2018 / \\ ISSN impreso 2390-0288, ISSN digital 2590-9398 / Bogotá, D.C., Colombia / pp. 138-149. \\ Fecha de recepción: 24 de mayo de 2017 \\ Fecha de aceptación: 9 de julio de 2017 \\ Doi: https://doi.org/10.14483/25909398.14212 \\ Cómo citar este artículo: Conde, G.M. (2018, enero-diciembre). Del paso de la guerra a las resistencias corporales. \\ Revista Corpo-grafías: Estudios críticos de y desde los cuerpos, 5(5), p-p 138-149 / ISSN 2390-0288. \\ *Artículo de investigación: Este artículo surge como parte de la reflexión teórica dentro de la tesis doctoral en \\ curso titulada: Prácticas corporales de la vida cotidiana, para la resignificación de la violencia vivida en el cuerpo de \\ mujeres víctimas del conflicto armado en Colombia, del Doctorado en Estudios Latinoamericanos de la Universidad \\ Nacional de La Plata, Argentina. \\ **Docente investigadora de la Facultad de Cultura Física, Deporte y Recreación de la Universidad Santo Tomás, Grupo \\ Cuerpo Sujeto y Educación; Estudiante de Doctorado en Estudios Latinoamericanos de la Universidad Nacional de \\ La Plata - Argentina, Magister en Desarrollo Educativo Social CINDE - Universidad Pedagógica Nacional y Educadora \\ Física de la Universidad Pedagógica Nacional.
}

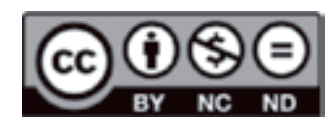




\section{Resumen}

El presente artículo surge como una reflexión del término de violencia y sus ramificaciones en el marco de las guerras contemporáneas, en particular del conflicto armado colombiano y como a pesar de sus impactos sobre los cuerpos de las mujeres víctimas, han surgido formas de resignificar la vida.

Palabras clave: estado; violencia; cuerpo; prácticas corporales; resistencias.

\section{Abstract}

The present article emerges as a reflection of the term of violence and its ramifications in the context of contemporary wars, in particular of the Colombian armed conflict and how, despite their impact on the bodies of women victims, ways of resignifying life have emerged.

Keywords: state; violence; body; corporal practices; resistances.

\section{Resumo}

O presente artigo emerge como reflexo do termo da violência e suas ramificações no contexto das guerras contemporâneas, em particular do conflito armado colombiano, e como, apesar de seu impacto sobre os corpos das mulheres vítimas, surgiram formas de ressignificação da vida.

Palavras-chave: estado; violencia; corpo; práticas corporais; resistências. 


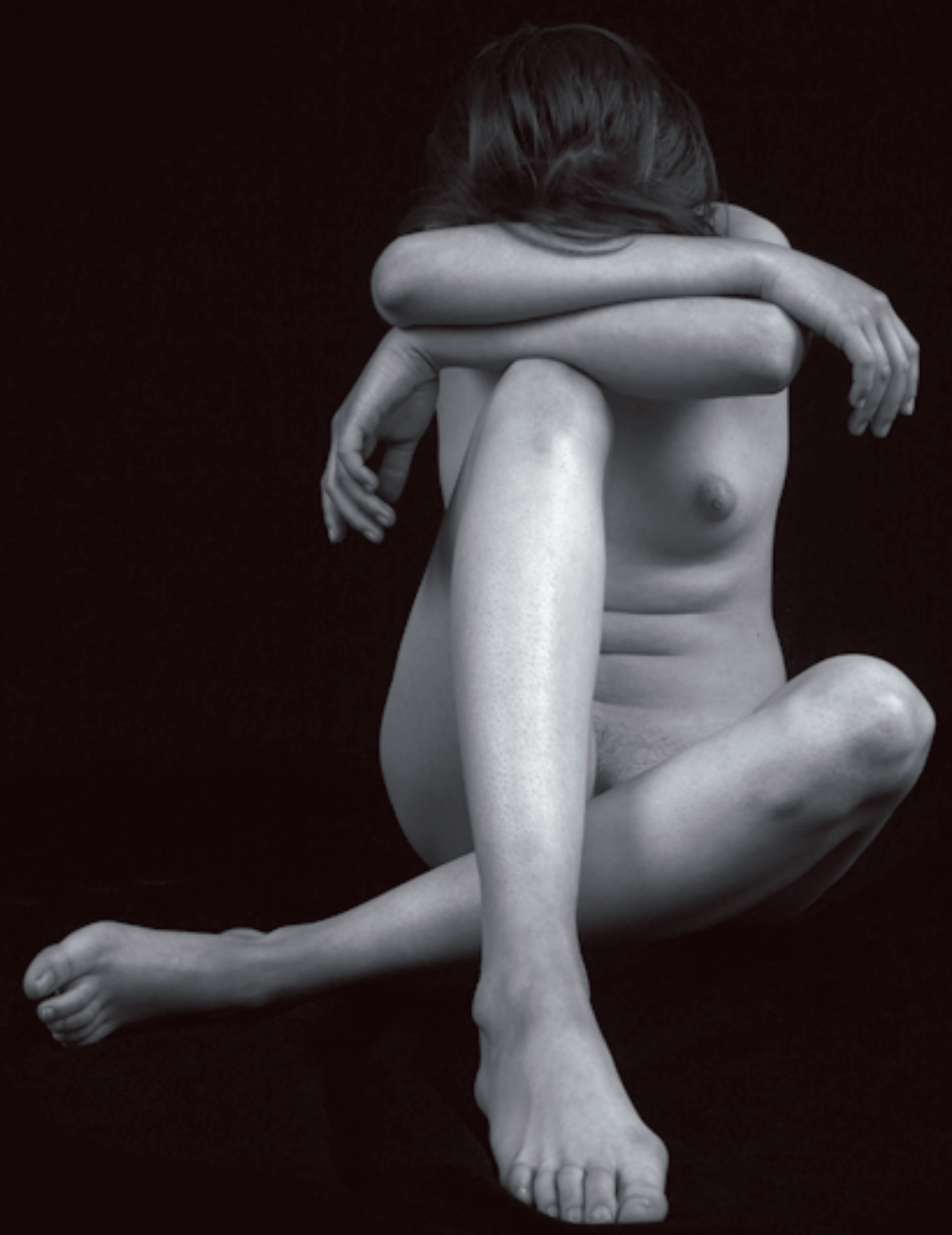

Realidad Corpórea 1

Érika Lara Parga

2016

El ser humano busca a través de las prendas ocultar su realidad. Con esta serie de fotografías busco desnudar no el cuerpo como materia, sino que a través de un proceso de reconocimiento y aceptación de las distintas dimensiones a las que se tiene que enfrentar el ser humano, se logra una desnudez que sale de lo profundo de la existencia, para llegar al fin último, desnudar el cuerpo material. 


\section{La razón de ser del Estado como regulador de la violencia}

Hobbes (1588 - 1679) consideró que todos los hombres son iguales por naturaleza, lo que conlleva un problema y es el de la competencia por los recursos para la sobrevivencia, de ahí que estén dadas las condiciones para una guerra "de todos contra todos" (Rivera, 1998, p.185). En la prevención de la guerra para la preservación de la paz, se funda el Estado o Leviatán, que es el pacto de unión entre todos los hombres para la conservación de la vida; entre sus funciones, el Estado debe ejercer violencia física sobre aquel que rompa el pacto, velando de esta manera por la seguridad de los hombres, es decir, que cada individuo renuncia al propio derecho de autodefensa y se da "un progresivo control de la agresividad de los individuos" (Hernández, 2011, p.131).

Jellinek (como se citó en Hernández, 2011) plantea que un Estado existe cuando tiene un territorio que es el espacio físico para profesar su dominación, cuenta con las personas que habitan el territorio, es decir, la población y ejerce poder para mantener tanto la soberanía interna como externa; un Estado es soberano cuando logra mantener la paz en su interior y proteger sus fronteras externas (Habermas, como se citó en Hernández, 2011); según esta última premisa, dentro de la lógica de la modernidad europea, Colombia no podría ser entendida como un Estado soberano, en razón de las dificultades que tiene para mantener una paz duradera y sostenible, considerando "la tendencia al debilitamiento de las instituciones estatales de prestación de servicios sociales, contraria al objetivo ético de fortalecerlas como patrimonio social, como bien colectivo de la sociedad" (Plataforma Colombiana de Derechos humanos, democracia y desarrollo, 2003, p.9) y, por ejemplo, al ceder partes de su territorio para la instalación de bases militares estadounidenses (Vallejo y Insuasty, 2009).

Hernández (2011), explica que la ausencia de soberanía en Colombia, tiene sus orígenes desde la colonia, que, si bien se ganó independencia de España, las dinámicas de "patrias chicas" apropiadas por familias, deslegitimaban la acción del Estado al no tener el "monopolio de la violencia" (p.132). Avanzando en el tiempo y adicional a lo anterior, Hernández aclara que los terratenientes locales y regionales, debilitaban el surgir del Estado en su resistencia a pagar impuestos sobre la tierra, además de resolver los conflictos con sus ejércitos privados y de autodefensa que hacían uso de la violencia; este tipo de prácticas llevaron al desarrollo de ocho guerras civiles que confluyeron en lo que históricamente se ha denominado como La Violencia y es en este punto de la historia de Colombia que el autor pone de presente dos propuestas interesantes, la primera de ellas sostiene que "en lugar de un Leviatán, que agencia como árbitro y tercero, los grupos locales de particulares más poderosos hacían las veces de Estado" (p.134); lo que tiene impacto sobre la segunda idea que está basada en Oquist (1980), al establecer la relación entre la debilidad del Estado con el surgimiento de la violencia.

Continuando con la línea del tiempo de la violencia en Colombia, explica Hernández (2011) que la ausencia de un poder "coercitivo soberano" (p.135) posibilita el surgimiento de grupos de autodefensas campesinas que pasan a ser las guerrillas de las FARC, y en oposición o en su defensa surgen grupos paramilitares, lo que de fondo genera un caos de todos contra todos; por su parte, Blair (2010), sostiene que hay lugares donde el Estado no logra llegar y es en estos territorios en donde se generan Estados paralelos, que ejercen sus propias y particulares formas de dominación por medio de la activación de la violencia. 


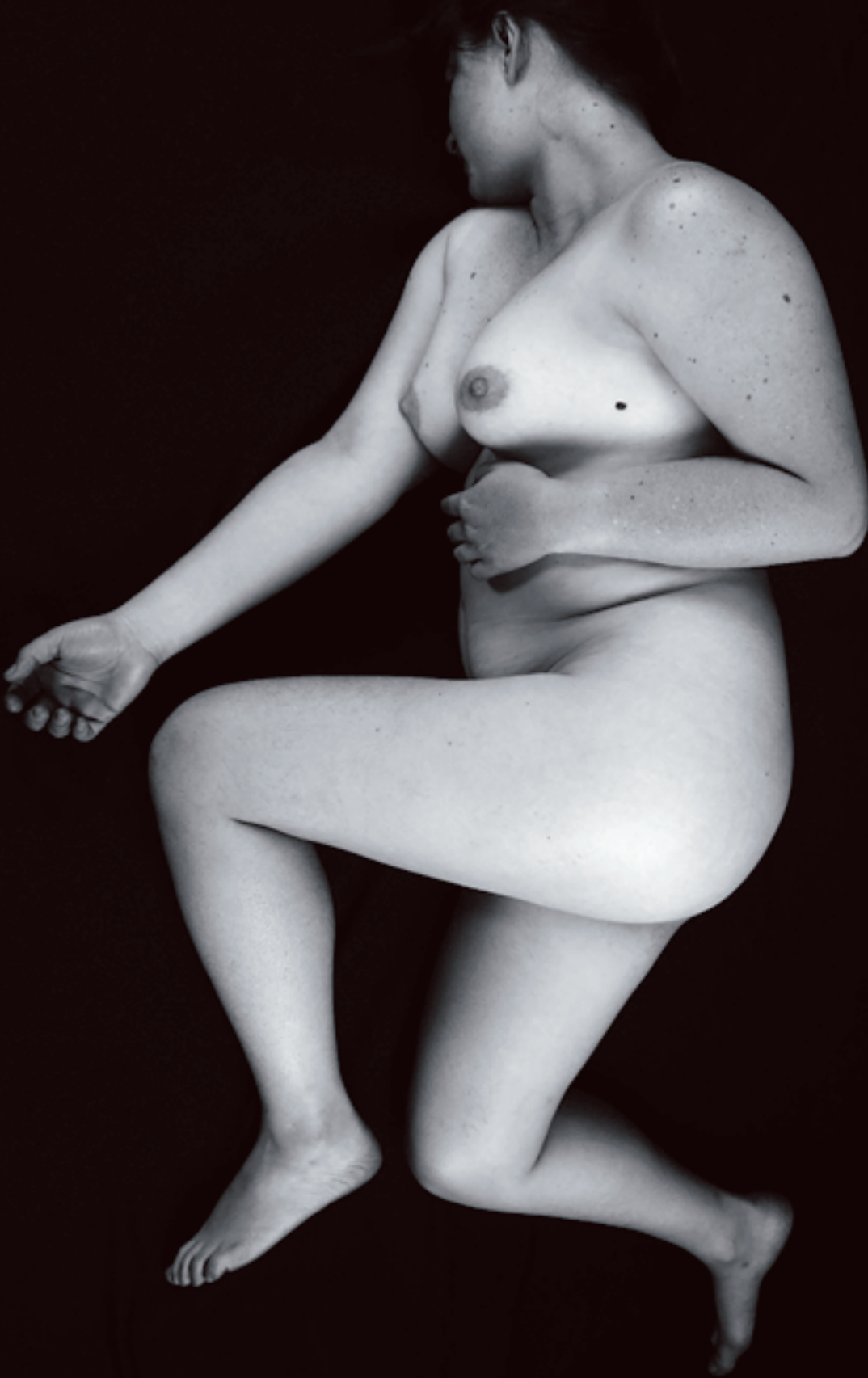

\section{El ejercicio de la violencia sobre los cuerpos}

El hablar de la violencia genera pensar que existen no solo una, sino múltiples formas en que los contextos sociales y culturales han creado diversos medios de afectar a los sujetos de manera individual y colectiva, de ahí que la violencia puede ser tipificada según el ámbito en el que se desarrolle y los fines que se busquen; a su vez, ahondar en la violencia significa que esta se transmite de manera tanto sutil como contundente y que de generación en generación se va naturalizando como un habitus connatural del ser humano (Blair, 2009), por lo tanto, transitar por la violencia en Colombia, implica comprender en primer lugar que es diacrónica por cómo se ha ido transformando en el tiempo y también sincrónica por las situaciones particulares de cada momento histórico (Betancourt, 2010).

Blair (2009) llama la atención sobre el relativismo histórico de la violencia, lo que corresponde a que cada época tiene sus propios rasgos de violencia ya que está en relación con las necesidades y luchas propias de cada sociedad; establece además que lo crítico de la violencia es que pone en riesgo la integridad del otro, la vida, la salud y/o su libertad, por lo tanto, la violencia es usar "una fuerza abierta o escondida, con el fin de obtener de un individuo o de un grupo eso que ellos no quieren consentir libremente" (Domenach, como se citó en Blair, 2009) a su vez, la violencia puede ocurrir en ámbitos públicos y privados y es posible focalizar la violencia según el género, la edad, la raza y los niveles socioeconómicos con lo que se comprende que la violencia es un "fenómeno multidimensional" (Blair, 2009). 
Cada institución social, genera sus propias formas de violencia para "domesticar, disimular y controlar la violencia, siempre presente en la vida social" (Girard, como se citó en Blair 2009); la violencia es ejercida de sujetos contra sujetos y es aplicada directamente sobre los cuerpos, produciendo memorias de dolor y sufrimiento, con lo que el mundo se puede dividir entre víctimas y victimarios. Chaux (2003) indica que la violencia es aprendida y que, para el caso colombiano, la violencia política influencia la vida cotidiana generando la violencia común, lo que profundiza según él el ciclo de violencia, que soporta en sí misma a la agresión y esta puede ser:

Física (cuando busca hacer daño físico a la persona), verbal (cuando se quiere herir a través de las palabras), relacional (cuando se busca hacerle daño a las relaciones que tiene la otra persona o al estatus social que tiene en su grupo), o de otras formas. (Chaux, 2003, p.49)

Añádase a lo anterior que la agresión se diferencia entre agresión reactiva y agresión instrumental, la primera de ellas hace referencia a una respuesta que se puede tomar frente a una ofensa real o percibida, mientras la segunda no está precedida de ninguna ofensa "es el uso de la agresión como un instrumento para conseguir un objetivo, sea este recurso, dominación, estatus social o algo más" (Chaux, 2003, p.49) que al ser trasladadas al contexto colombiano se obtiene que los grupos armados hacen uso de la violencia para conseguir sus objetivos y esto legitima la agresión de tipo instrumental, de manera análoga el uso de la violencia como reacción legaliza la venganza, es decir ser contestatario frente a la agresión.

Además, la violencia surge como un mecanismo para que exista el auto control, que trasciende del ámbito privado hacia lo público cuando se logra poner "mis ojos" sobre el comportamiento de los demás y de esta forma "me habilita" como autoridad sobre el cuerpo del otro, de ahí que la violencia es una acción política que viabiliza la comprensión de que el otro no es un sujeto sino un objeto, que es "mi posesión"; tipificar la violencia posibilita la comprensión de los fines que esta busca y también ayuda a establecer los dispositivos con los cuales es ejercido el poder para "modelar, controlar y asegurar los gestos, las conductas, las opiniones y los discursos de los seres vivos" (Agamben, 2011, p.261), es decir producir subjetivaciones, lo que posibilita la gobernabilidad.

Blair (2010) va un poco más lejos en el análisis, al explicar que la violencia extrema en las guerras contemporáneas no se ejerce únicamente de un ejército sobre otro sino también sobre la población civil, que por medio del pleno deseo instrumental de la dominación de los territorios geográficos, se aplican dispositivos de control y dominación sobre los territorios personales, es decir, sobre los cuerpos a través del infligir dolor, entonces surge la crueldad concebida como la banalización del cuerpo del otro por medio de la profanación que "es la violación de lo sagrado y lo sagrado es el cuerpo, el que le da identidad a la víctima y que va a caracterizar el uso político de la crueldad" (Nahoum-Grappe, como se citó en Blair, 2010).

De ahí que lo que emergen son micropolíticas de poder sobre los cuerpos, afinando los dispositivos "en dos formas: una parcial (torturar, infligir dolor físico y psíquico; fragilizar la potencialidad defensiva del otro, provocando todo tipo de sufrimiento), y una total (provocar la muerte)" (Berezin como se citó en Blair, 2010); con ello la capacidad de producir subjetivaciones por medio del castigo despoja al sujeto de su valía, generando una pedagogía corporal centrada en el miedo cuyas didácticas se basan en el disciplinamiento, que cumple entonces con el objetivo de callar, domar y someter, al cual Betancourt, Peña y Rodríguez (2013) lo han denominado como las Pedagogías del Terror, cuyas tecnologías para infligir dolor van de las menos a las más directas: los desplazamientos, las desapariciones, las minas anti-persona, las torturas, las violaciones o la violencia sexual en el contexto de la guerra, las mutilaciones corporales y las masacres (Blair, 2010, pp.49-58). 


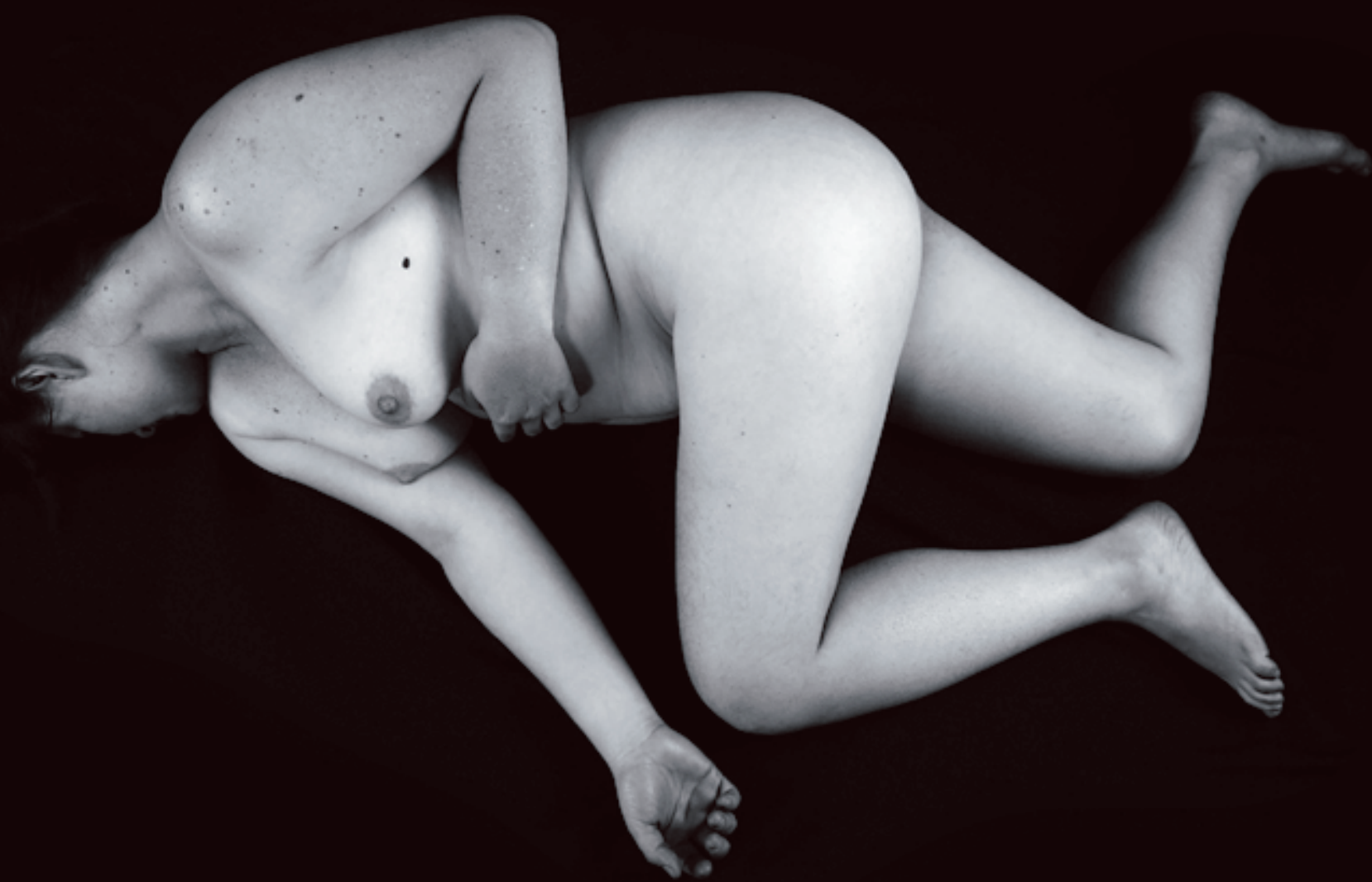

Si bien la violencia ha encontrado formas de perpetuarse y se puede hacer la lectura del mundo como un lugar sombrío en donde los seres humanos afinan las maneras de ejercer la violencia los unos sobre los otros, también es cierto que al interior de las comunidades surgen elementos para la preservación de la vida, en donde "el cuerpo se presenta como contradictorio y casi paradójico: lugar de la vida y de la muerte, de creación y destrucción, de intensa alegría y profunda tristeza" (Cabra y Escobar, 2014, p.133).

\section{Los impactos de la guerra en el cuerpo y subjetividad de las mujeres}

Dentro del marco de las guerras contemporáneas y en particular la guerra en Colombia, la literatura ha demostrado como los cuerpos de las mujeres ha sido los que han padecido modos particulares de violencia (física, psicológica, sexual, económica - patrimonial y simbólica) que se producen por efecto de hechos tales como las masacres, el desplazamiento forzado, violaciones sexuales como acciones de guerra, torturas; lo que ha agudizado su exclusión de los derechos civiles y políticos, sociales, económicos y culturales. Estos hechos han sido tipificados en la Sentencia 092 de 2008 como los diez (10) riesgos de género a los que se exponen las mujeres en el marco del conflicto armado colombiano: (i) el riesgo de violencia sexual, explotación sexual o abuso sexual en el marco del conflicto armado; (ii) el riesgo de explotación o esclavización para ejercer labores domésticas y roles considerados femeninos en una sociedad con rasgos patriarcales, por 
parte de los actores armados ilegales; (iii) el riesgo de reclutamiento forzado de sus hijos e hijas por los actores armados al margen de la ley, o de otro tipo de amenazas contra ellos, que se hace más grave cuando la mujer es cabeza de familia; (iv) los riesgos derivados del contacto o de las relaciones familiares o personales -voluntarias, accidentales o presuntas- con los integrantes de alguno de causa de su condición femenina en el marco de la confrontación armada interna colombiana y que no son compartidos por los hombres. (v) los riesgos derivados de su pertenencia a organizaciones sociales, comunitarias o políticas de mujeres, o de sus labores de liderazgo y promoción de los derechos humanos en zonas afectadas por el conflicto armado; (vi) el riesgo de persecución y asesinato por las estrategias de control coercitivo del comportamiento público y privado de las personas que implementan los grupos armados ilegales en extensas áreas del territorio nacional; (vii) el riesgo por el asesinato o desaparición de su proveedor económico o por la desintegración de sus grupos familiares y de sus redes de apoyo material y social; (viii) el riesgo de ser despojadas de sus tierras y su patrimonio con mayor facilidad por los actores armados ilegales dada su posición histórica ante la propiedad, especialmente las propiedades inmuebles rurales; (ix) los riesgos derivados de la condición de discriminación y vulnerabilidad acentuada de las mujeres indígenas y afrodescendientes; $\mathrm{y}$ ( $\mathrm{x}$ ) el riesgo por la pérdida o ausencia de su compañero o proveedor económico durante el proceso de desplazamiento. Aunado a esto, Segura

\& Marteens (1997) explican que:

Las mujeres parecen ser más vulnerables en el momento del desarraigo, expuestas intempestivamente a la viudez, las amenazas, la clandestinidad, la huida, el quiebre de relaciones primarias organizadas en torno a lo doméstico, en fin, el abandono del entorno familiar físico y social. Los hombres parecen estar mejor equipados para afrontar este momento y las pérdidas y dificultades iniciales. (p.18)

Estas vulnerabilidades, han desembocado en repercusiones que desde la perspectiva de las víctimas van más allá del conteo de muertos y la destrucción material, ya que los daños han alterado profundamente los proyectos de vida de miles de personas y familias. El informe ¡Basta ya! Colombia: Memorias de guerra y dignidad (Histórica, 2013), expone, además, que los impactos pueden ser incuantificables e incluso intangibles, dentro de cuatro categorías: daños emocionales y psicológicos, daños morales, daños políticos y daños socioculturales.

\section{Las resistencias corporales}

A pesar de las configuraciones de autoridad dominante, en Colombia han surgido formas de resistencia, comprendida esta como la defensa de la existencia, por medio de mecanismos no violentos, colectivos y organizados (Hernández, 2009) provenientes de minorías sociales que han construido a lo largo de tiempo estrategias para la preservación de su soberanía, un ejemplo de ello es la comunidad Nasa, ubicada en el departamento del Cauca, quienes crean prácticas de autoridad emancipatoria entendida como aquella que es reconocida por un colectivo, alejándose "del dominio de uno sobre el otro a un ejercicio [...] en el encuentro con otros" (Greco, 2011, p.89).

Para el año 2008, la comunidad Nasa logra llegar al Distrito Capital de Bogotá en una Minga de Resistencia Social y Comunitaria en la que convergen desde sus diferencias los cortadores de caña de azúcar, los empleados judiciales, los estudiantes y los camioneros, todos juntos para enunciar un “No al Modelo Económico Transnacional y no a los Tratados de Libre Comercio" (Valle, 2016); este encuentro fue 


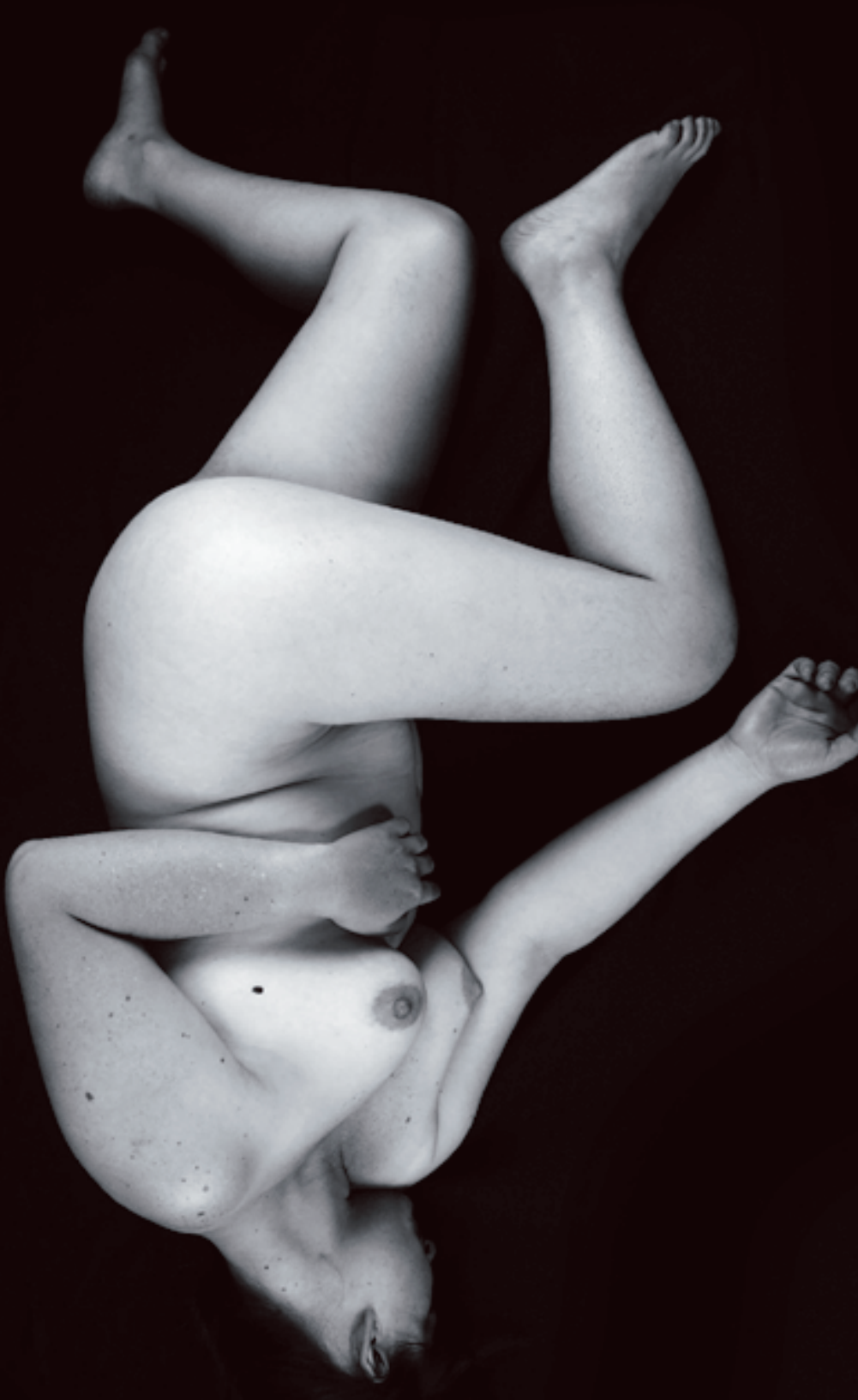

un precedente que llama a la consciencia sobre la soberanía, que además aproxima a los sectores sociales y es así como a través del ejemplo los indígenas se posicionan en Colombia como un nuevo referente de autoridad desde el diálogo y la concertación, siendo este un llamado a aprender nuevas prácticas de convivencia, al introducirse en el mundo del otro para comprender los efectos de interacción para construir con otros (Greco, 2011); el anterior es un ejemplo de lo que como colombianos se ha de explorar para encontrar nuevas formas de interacción que trascienden la heridas de la guerra, para la re-significación del conflicto y de esta manera restaurar el tejido social desde la diferencia.

De otra parte, Brajas (2016), explica que los sujetos traumatizados por los efectos de la guerra, "poseen y usan recursos propios de índole social, simbólica y corporal, con los que han afrontado de manera creativa las acciones violentas" (p.254), es decir que más allá de la intervención del Estado como ente responsable de la reparación económica, restitución de derechos y trabajo psicosocial, cada sujeto tienen en sí mismo la capacidad de reconocer la valía y lo valeroso que se es ante situaciones violentas y victimizantes; puede esto estar en relación con la necesidad vital de prevalecer bajo la idea de "hay que seguir adelante", entonces encontrar los propios recursos conllevaría a una acción práctica en términos de resolver la vida cotidiana, ordenando fines, proyectos y tareas unidas a emociones que se incorporan en el cuerpo para hallar nuevos modos de ser y de estar en el mundo.

De las ideas planteadas hasta ahora en este apartado, se puede establecer entonces que, la resistencia hace un tránsito bilateral de lo individual a lo colectivo y viceversa, en donde se ejerce una defensa pacífica tanto del territorio corporal como del territorio geográfico, por medio de la realización de prácticas que propician el empoderamiento en la promoción de la autonomía hacia la construcción de posibilidades de crecimiento y cambio personal (Saldanha y Signorini, 2016); en el caso particular de las mujeres en Colombia se dan dos prácticas de resistencia, entre muchas, que bien vale la pena rescatar en razón de la trascendencia política como respuesta no reactiva ante actos de violencia; el primero de ellos es el de Las Musas de Pogue, en el que por medio de alabaos las catadoras logran rescatar la memoria de lo acontecido y además los saberes de sanadores y curanderos de la región (Orjuela, 2016). 
La segunda experiencia es la de las mujeres víctimas de los falsos positivos y de crímenes políticos que se reúnen en el Centro de Memoria Paz y Reconciliación, en Bogotá y conforman desde el 2008 lo que se ha denominado como el Costurero de la Memoria, que se configura como "una experiencia de reconciliación a través del arte, es una manera de zurcir el duelo" (CINEP, 2017); ambas experiencias surgen de prácticas de la vida cotidiana: el cantar y el zurcir, para pasar de la guerra a las resistencias corporales como actos políticos creativos de las mujeres, al cuestionar de manera crítica a la cultura patriarcal que ha naturalizado la violencia, por lo tanto se genera un cambio profundo en la forma de concebir y asumir lo que significa ser hombre y ser mujer en Colombia (Cabra y Escobar, 2014).

\section{Conclusiones}

El Estado colombiano ha tenido dificultades históricas para lograr un poder coercitivo soberano, lo que ha posibilitado la generación de autodefensas y el ataque de todos contra todos, favoreciendo así la generación de Estados paralelos en donde cada uno crea sus propias formas de hacer justicia a través de la activación de la violencia.

La violencia es difícil de conceptualizar ya que cada momento histórico crea sus propias formas de accionarla lo que la hace sincrónica, pero a su vez es diacrónica por las transformaciones que va teniendo en el tiempo; además hay que intentar comprender la violencia como un fenómeno multifactorial, en donde se entrecruzan elementos de género, raza, edad y territorio.

La violencia en el marco de las guerras contemporáneas, se caracteriza por el ataque directo sobre la población civil, que despliega una serie de tecnologías corporales que cruzan la crueldad, lo que doblega al cuerpo y le hace perder su estado de sacralidad.

A pesar de la política punitiva sobre el cuerpo que caracteriza a la guerra en Colombia, surgen formas de resistencia colectiva e individual que de manera pacífica, busca reivindicar al sujeto en su valía a partir de actos políticos creativos.

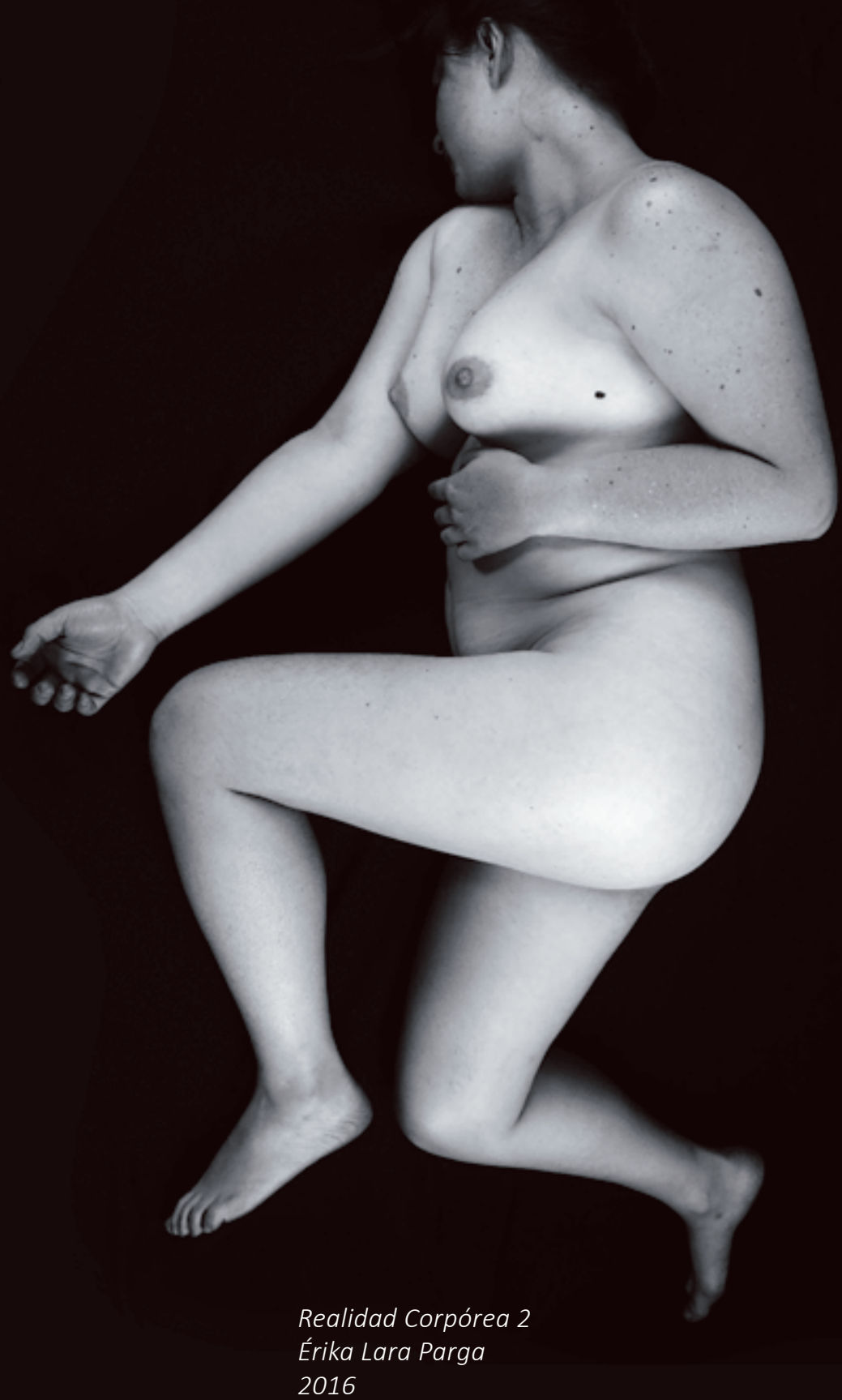




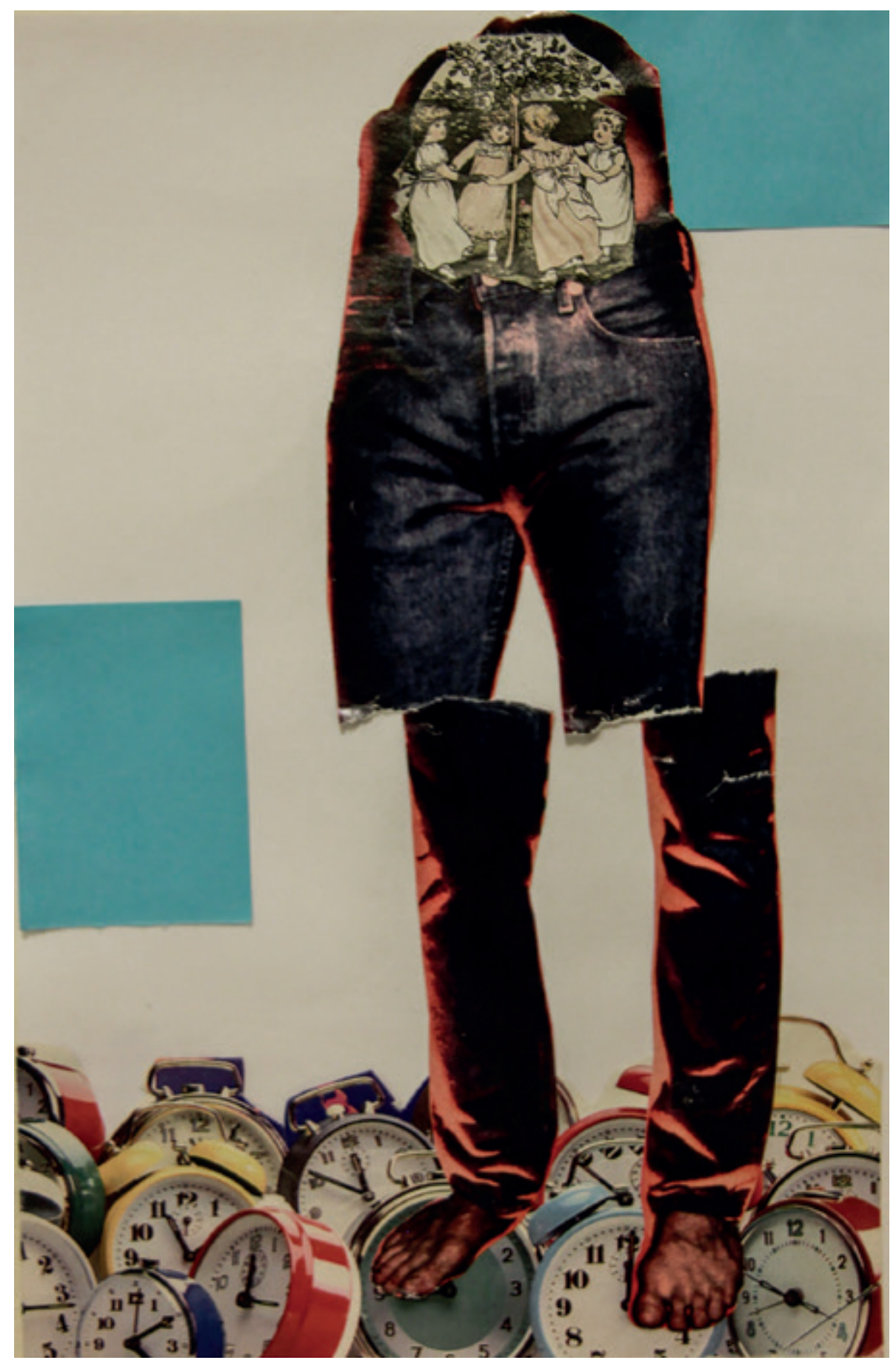

Fragmentado

Érika Lara Parga

Técnica: collage

2018

En un sistema demandante, que nos deja sin tiempo, el ser humano se remite a una existencia hermética y quebrada, su vida, se limita a retener dentro de si su capacidad de asombro y deseo, para cumplir con la imposición del sistema que demanda tiempo y asume la negación del ser. 


\section{Referencias}

Agamben, G. (2011). “¿Qué es un dispositivo?” Sociológica (México), 26(73), pp.249-264.

Barajas, L. C. (2016). “Prácticas sociales y cuerpos recuperados: Reconfigurar lo propio para sobrevivir”, Nómadas, (45), pp.253-262.

Betancur, J. G. (2010). “Conflicto Armado Interno vs. Amenaza Terrorista: La Disputa por un Concepto”, Reflexión Política, (24), pp.68-77.

Betancourt, S., Peña, J., \& Rodríguez, P. (2013). Memoria encarnada del conflicto armado colombiano. (Maestría), CINDE - Universidad Pedagógica Nacional, Bogotá D.C.

Blair, E. (2009). "Aproximación teórica al concepto de violencia: Avatares de una definición", Política Y Cultura, (32), pp.9-33.

Blair, E. (2010, enero-junio). "La política punitiva del cuerpo: "economía del castigo" o mecánica del sufrimiento en Colombia”, Estudios Políticos, 36, pp. 39-66, Instituto de Estudios Políticos, Universidad de Antioquia.

Cabra, N., y Escobar, R. (2014). El cuerpo en Colombia: estado del arte cuerpo y subjetividad, Bogotá: IESCO: IDEP, 2014.ISBN: 978958-26-0207-9

Castrillón, G. L., Riveros, F. V., Knudsen, M.L., López, Lo. W., Correa, Ch. A., y Castañeda, J.G. (2018). “Comprensiones de perdón, reconciliación y justicia en víctimas de desplazamiento forzado en Colombia", Revista de Estudios Sociales, 63, pp.84-98. En línea: https:// dx.doi.org/10.7440/res63.2018.07

Chaux, E. (2003). “Agresión reactiva, agresión instrumental y el ciclo de la violencia”, Revista de Estudios Sociales, (15), pp.47-58.

CINEP. (2017). Costurero de la memoria, reconciliar a través del arte, Recuperado de https://goo.gl/WKg1VK

Corte Constitucional. (2008). Auto 092/08: Adopción de medidas para la protección a mujeres víctimas del desplazamiento forzado por causa del conflicto armado, Bogotá: Corte Constitucional.

Greco, M. B. (2011). “Una autoridad emancipatoria: volver a pensar la autoridad en tiempos de transformación”, n R. Maliandi. (Comp.), Actas de las III Jornadas Nacionales de Ética y I Jornadas Interdisciplinarias UCES: sobre la Autoridad: perspectivas interdisciplinarias y prácticas sociales, pp. 85-90, Buenos Aires: FUCES.

Hernández, E. (2009). “Resistencias para la Paz en Colombia. Experiencias indígenas, afrodescendientes y campesinas”, Revista De Paz Y Conflictos, 2, pp.117-135.

Hernández, J. A. (2012). “El behemoth Colombiano: Teoría del Estado, violencia y paz”, Revista de Estudios Sociales, 42, pp.129-137.

Histórica, G. d. M. (2013). ¡Basta ya! Colombia: Memorias de guerra y dignidad, Informe General Grupo de Memoria Histórica, Colombia: Centro Nacional de Memoria Histórica.

Molina, N. (2004). "Resistencia comunitaria y transformación de conflictos. Un análisis desde el Conflicto político-armado colombiano", Athenea Digital, 1(6).

Orjuela, C. (07 de marzo de 2018) Pogue: la memoria hecha de cantos. Centro Nacional de Memoria Histórica, recuperado de https://goo. $\mathrm{gl} / \mathrm{SQV} 77 \mathrm{f}$

Plataforma Colombiana de Derechos humanos, democracia y desarrollo. (2003). El embrujo autoritario primer año de gobierno de Álvaro Uribe Vélez.

Rivera, A. (1998). "Thomas Hobbes: modernidad e historia de los conceptos políticos”, Res pública, 1, pp. 183 - 198.

Saldanha, A., y Goncalves, S. (2016). "Praticas de empoderamento feminino na America Latina”, Revista De Estudios Sociales, (56), p.80.

Segura, N., y Meertens, D. (1997). “Desarraigo, género y desplazamiento interno en Colombia”, Nueva Sociedad, 148, pp.30-43.

Valle, V. (9 al 14 de octubre de 2016). Los proyectos de "los dueños sin pueblos" y las propuestas de "los pueblos sin dueño", recuperado de http://pueblosencamino.org/?p=3485

Vallejo, Y. y Insuasty, A. (2009). “¿Independencia?” Revista Kavilando, 1(2), pp.11-16. 